\title{
To compare the severity of the premenstrual syndrome in urban and rural population
}

\section{Gupta $\mathbf{B}^{1}$.}

${ }^{1}$ Dr Bhavana Gupta, Professor, Department of Obstetrics and Gynaecology, Integral Institute of Medical Sciences, Dasauli, Kursi Road, Lucknow. Uttar Pradesh, India.

Address for Correspondence: Dr Bhavana Gupta, Email: bhavana_yajat@yahoo.com

\section{Structured Abstract}

Introduction: The premenstrual syndrome causes considerable morbidity to women. It is a silent epidemic which needs attention to provide quality of life to urban and rural women. Objective: To compare the severity of the premenstrual syndrome in urban and rural population $n$ the age group of 15-35 years and to study the selected variables and the relationship to premenstrual syndrome. Methods: The cross-sectional study was carried out in the department of obstetric and gynecology at Integral institute of medical sciences and research, Lucknow from January 2016 to July 2016 for the period of 6 months.300 women (150 each for rural and urban population) from the age group of 15-35 years were given questionnaire (Modified Moos Menstrual Distress Questionnaire) and the results were compared using $\mathrm{t}$ and $\mathrm{p}$ value. The relationship of the variables like age, education, parity, socioeconomic status, education of the subjects mother, characteristic features of the menstrual cycle were assessed. Result: The severity of premenstrual syndrome is more in urban population than rural population. The severity of PMS was directly proportional to age, parity, educational status, socioeconomic status. The severity of dysmenorrhoea was proportional to severity of PMS. Conclusion: PMS is more severe in urban population. The severity increases with age, parity, educational status, and socioeconomic status and dysmenorrhoea.

Keywords: Premenstrual Syndrome, Menstrual cycle, Dysmenorrhoea

\section{Introduction}

The Premenstrual Syndrome refers to physical and emotional symptoms that occur in the one or two weeks before a women menstrual period. The symptoms often vary between women and resolve around with the starting of menstrual bleeding. The common symptoms include acne, tender breasts, bloating, feeling tired, irritability and mood changes. Often symptoms are present for around six days. The symptoms do not occur during pregnancy or following menopause $[1,2]$.

The diagnosis is consistent pattern of emotional and physical symptoms occurring after ovulation and before menstruation to a degree that interferes with normal life. The type of personality and environmental factors affect the development of symptoms. The criteria for PMS are [2]:

a. The symptoms occur in the second half of menstrual cycle.

b. The symptoms free period of at least 7 days in the first half of the cycle.

\footnotetext{
Manuscript received: $7^{\text {th }}$ December 2016

Reviewed: $16^{\text {th }}$ December 2016

Author Corrected: $24^{\text {th }}$ December 2016

Accepted for Publication: $31^{\text {st }}$ December 2016
}

Obsgyne Review: Journal of Obstetrics and Gynecology c. The symptoms most occur in each of the three consecutive cycles.

d. The symptoms are severe enough to require medical help.

$80 \%$ of women experiences some discomfort before the menses. About $20-30 \%$ of them are related to PMS. Premenstrual dysphoric disorder (PMDD) affects 3-8\% of premenstrual women. Antidepressant medications like selective serotonin reuptake inhibitor are used to treat $[1,2,3]$. The Moos Menstrual Distress Questionnaire was introduced in 1968. It was shown that Moos factors effectively represent the structure of menstrual cycle symptoms [4].

\section{Material and Methods}

The Cross-sectional study was carried out in the department of obstetrics and gynecology at Integral institute of medical sciences and research, Lucknow from January 2016 to July 2016, for the period of 6 months. 300 women (150 each for rural and urban population) from the age group of 15-35 years were given questionnaire (Modified Moos Menstrual Distress

$$
\text { Available online at: www.medresearch.in } 70 \mid \mathrm{P} \text { a g e }
$$


Questionnaire).The sample size was collected by complete enumeration. The continuous and categorical variables were studied and the results were statistical analysed by using $t$ and $p$ value.

Exclusion criteria: women with psychiatric illness. The reason for the below classification was, the women in reproductive period were taken into consideration and women in perimenopausal period were not taken into consideration, as climacteric and menopausal symptoms can alter the findings.

Group A: 75 women of urban population with 15-25 years.

Group B: 75 women of rural population with 15-25 years.

Group C: 75 women of urban population with 26-35 years.

Group D: 75 women of rural population with 26-35 years.

Group A and Group B, Group C and Group D were comparable. Each woman after informed consent was given Modified Moos Menstrual Distress Questionnaire.

\section{Original Research Article}

The questionnaire included preliminary data-The parameters included were: Age, religion, marital status, parity, Income, profession, education and occupation of head of family, mothers education, socioeconomic status was taken by modified Kuppuswamy score which included occupation of head of family and income. The details of menstrual history was taken which included age of menarche, length of menstrual cycle, duration of menstruation. The PMS was assessed with 8 clusters of symptoms with 47 items.

These clusters were pain, concentration, behavior changes, autonomic reaction, water retention, negative affect, arousal and self control.

Each of the 47 items had 3 responses: Never, Sometimes, Always with $0,1,2$ scores respectively. The mean PMS score of different group were evaluated and compared with $t$ and $p$ value. The relationship of the variables like age, education, parity, socioeconomic status, education of the subjects mother, characteristic features of the menstrual cycle were assessed.

\section{Result}

The age of 300 subjects of rural and urban population was 15-35years. The age in group A, group B, group C and group D were $20,30.65,22,44$ and 30.55 years respectively. $75 \%$ of subjects had parity between $1-4$. $80 \%$ of urban population belonged to middle and high socio economic class. 50\% 0f rural population belonged to lower socioeconomic class. Most of the subjects had menses for 3-5 days, at an interval of 28 -30 days. Table 1, shows the PMS score in urban population was significantly higher than in rural population for both age groups, $\mathrm{p}<0.001$. In table 2 , the mean PMS score of age group 26-35 years was significantly higher than both population in 15-25 years. In table 3 , the PMS score in women with parity more than 4 was higher compared to nulliparous and women with parity 1-3. The score of women with parity 1-3 was higher compared to nulliparous. The PMS score was higher in high socioeconomic group than low and middle class group, in Table 4.The PMS score was high in subjects with severe dysmenorrhoea.

Table-1: Comparison of PMS score of rural and urban population.

\begin{tabular}{|c|c|c|c|c|c|}
\hline Age & Group & No. of subjects & Mean +SD & t & p \\
\hline $15-25$ & A & 75 & $9.52+3.28$ & & $<0.0001$ \\
& B & 75 & $19.44+6.28$ & 12.1560 & $<0.0001$ \\
\hline $26-35$ & C & 75 & $11.68+5.12$ & & 25.19 \\
& D & 75 & $26.58+0.1$ & & $<$ \\
\hline
\end{tabular}

Table-2: Comparison of PMS score according to age in both groups

\begin{tabular}{|c|c|c|c|c|c|c|}
\hline Group & Age (Years) & No. of cases & Range & Mean +SD & t & p \\
\hline Rural & $15-25$ & 75 & $0-16$ & $9.52+3.28$ & 3.07 & 0.0025 \\
& $26-35$ & 75 & $0-20$ & $11.68+5.12$ & & $<0.0001$ \\
\hline & $15-25$ & 75 & $2-29$ & $19.44+6.26$ & 9.87 & \\
\hline
\end{tabular}


Table-3: Comparison of PMS according to parity in both groups.

\section{Original Research Article}

\begin{tabular}{|c|c|c|c|c|c|c|c|}
\hline Group & Parity & No. of cases & Range & Mean +SD & Comparison & t & p \\
\hline Rural & & & & & & & \\
1 & 0 & 29 & $0-15$ & $7.0+3.25$ & 1 vs 2 & 3.77 & 0.0003 \\
2 & $1-3$ & 87 & $0-20$ & $9.2+2.52$ & 1 vs 3 & 7.2 & $<0.0001$ \\
3 & $>/ 4$ & 34 & $5-19$ & $12.50+2.8$ & 2 vs 3 & 6.27 & $<0.0001$ \\
\hline Urban & & & & & & & \\
1 & 0 & 46 & $2-34$ & $17.81+7.15$ & 1 vs 2 & 4.70 & $<0.0001$ \\
2 & $1-3$ & 90 & $6-45$ & $23.96+7.25$ & 1 vs 3 & 5.33 & $<0.0001$ \\
3 & $>/ 4$ & 14 & $12-44$ & $30.27+9.18$ & 2 vs 3 & 2.91 & 0.0043 \\
\hline
\end{tabular}

Table-4: Comparison of PMS score according to socio-economic status in both the groups.

\begin{tabular}{|c|c|c|c|c|c|c|c|}
\hline Group & SES & No. of cases & Range & Mean +SD & Comparison & $\mathbf{t}$ & $\mathbf{p}$ \\
\hline \multicolumn{8}{|l|}{ Rural } \\
\hline 1 & Low & 10 & $20.31+10.77$ & $5-44$ & 1 vs 2 & 9.80 & $<0.0001$ \\
\hline 2 & Middle & 90 & $8.99+1.22$ & $2-36$ & 1 vs 3 & 3.12 & 0.0028 \\
\hline 3 & High & 50 & $12.41+6.47$ & $6-45$ & 2 vs 3 & 4.87 & $<0.0001$ \\
\hline \multicolumn{8}{|l|}{ Urban } \\
\hline 1 & Low & 92 & $9.56+3.78$ & $0-18$ & 1 vs 2 & 3.99 & $<0.0001$ \\
\hline 2 & Middle & 44 & $12.25+3.43$ & $0-18$ & 1 vs 3 & 7.86 & $<0.0001$ \\
\hline 3 & High & 14 & $17.75+2.31$ & $15-20$ & 2 vs 3 & 5.59 & $<0.0001$ \\
\hline
\end{tabular}

\section{Discussion}

Premenstrual syndrome (PMS) is a recurrent luteal-phase condition characterized by physical, psychological, and behavioral changes of sufficient severity to result in deterioration of interpersonal relationships and normal activity. Premenstrual dysphoric disorder (PMDD) is considered a severe form of PMS [1,2]. The definitive cause of PMS is unknown. Incorrect older theories about the causes of PMS include estrogen excess, estrogen withdrawal, progesterone deficiency, pyridoxine (vitamin B6) deficiency, [3,4] alteration of glucose metabolism, and fluid-electrolyte imbalances. Current research provides some evidence supporting the following etiologies:

- Serotonin deficiency is postulated because patients who are most affected by PMS have differences in serotonin levels; the symptoms of PMS can respond to selective serotonin reuptake inhibitors (SSRIs), which increase the amount of circulating serotonin

- Magnesium and calcium deficiencies are postulated as nutritional causes of PMS; studies evaluating supplementation show improvement in physical and emotional symptoms

- Women with PMS often have an exaggerated response to normal hormonal changes; although their levels of estrogen and progesterone are similar to those of women without PMS, rapid shifts in levels of these hormones promote pronounced emotional and physical responses.

Obsgyne Review: Journal of Obstetrics and Gynecology
- Other theories under investigation include increased endorphins, alterations in the gamma-aminobutyric acid (GABA) system, and hypoprolactinemia $[5,6,7]$.

The studies suggest that the experience of abuse (emotional, sexual, or physical) in early life places women at higher risk for PMS in the middle-to-late reproductive years [8]. Inability to maintain normal activities is part of the definition of this disease; hence, morbidity is related to loss of function. Complications of PMS may include school absence and behavioral problems. PMS and PMDD have been associated with a higher risk of bulimia nervosa [9]. PMS may also be associated with an increased risk of future hypertension [10].

Behavioral counseling and stress management may help the patients regain control during times of high emotionalism. Relaxation techniques may also help. Areas of stress should be identified. Relaxation techniques such as yoga, biofeedback, and self-hypnosis may be beneficial.

Regular exercise often decreases the symptoms of PMS. Patients should be counseled to avoid salt, caffeine, alcohol, and simple carbohydrates Most PMS symptoms worsen with the patient's age until menopause; thus, little good news can be given to severely affected adolescents. 
In the study the PMS score was higher in urban group than rural group in both the age groups which is in accordance with the finding by Biggs et al (2011) Parveen Marwah et al (2007) [1, 2]. The urban women with stressful life and multitasking might be responsible for the high PMS score.

The extent to which the daily activities are considered as undesirable and stressful, and the knowledge of PMS influenced the severity and perception of PMS.

The positive association between premenstrual symptoms and age and parity was also found in some of the other studies $[3,4]$. It may be that the underlying endocrine changes of the cycle remain constant throughout reproductive life but that the women's tolerance diminishes as the stress in life increases. Increased work and family stress, increased family size may be the cause of high PMS score.

The premenstrual symptoms increases with with level of education as supported by some of the studies $[5,6,7]$. It is likely that educated women are more aware and can communicate the symptoms related to menstrual cycle. The PMS is more severe in higher socio economic group $[8,9]$.

The severity of PMS and dysmenorrhoea are directly associated and can be understood by the effectiveness of cyclooxygenase inhibitors in relieving the both [10].

Funding: Nil, Conflict of interest: Nil

Permission from IRB: Yes

\section{References}

1. Biggs WS, Demuth RH. Premenstrual syndrome and premenstrual dysphoric disorder. Am Fam Physician. 2011 Oct 15;84(8):918-24.

\section{Original Research Article}

2. Parveen Marwah, Urvashi Gandi, Harpreet Kaur. Assessment and comparison of the premenstrual syndrome in urban and rural population. Asian Journal of OBS \& Gyn Practice. 2007; Vol11,No.3,July-Sep,pg7-11.

3. Dickerson LM, Mazyck PJ, Hunter MH. Premenstrual syndrome.Am Fam Physician. 2003Apr15;67(8):1743-52.

4. C. Ross, G. Coleman, C. Stojanovska. Personality and psychological factors affecting Premenstrual Syndrome. Journal of Psychosomatic Obstetric and Gynaecology. 2003; vol24, Issue3, 163-174.

5. Marván ML, Díaz Eroza MC. Premenstrual symptomatology in rural and urban zones. Acta Psiquiatr Psicol Am Lat. 1995 Dec; 41(4):316-21.

6. Fontana AM and Badawy S. Perceptual and coping processes across the menstrual cycle: An investigation in a premenstrual syndrome clinic and community sample. Behav. Med.1997:22(4)152-159.

7. Marván ML, Díaz-Erosa M, Montesinos A. Premenstrual symptoms in Mexican women with different educational levels. J Psychol. 1998 Sep;132(5):517-26.

8. Woods NF, Most A, Longenecker GD. Major life events, daily stressors, and perimenstrual symptoms. Nurs Res. 1985 Sep-Oct;34(5):263-7.

9. Clare AW. Psychaitric and social aspects of premenstrual complaint. Psychol Med., Monograph (suppl 4) Cambridge University press 1983.

10. Budoff PW. Zomepirac sodium in the treatment of primary dysmenorrhea syndrome. N Engl J Med. 1982 Sep 16; 307 (12): 714-9.

\section{How to cite this article?}

Gupta B.To compare the severity of the premenstrual syndrome in urban and rural population. Obs Rev:J obstet Gynecol 2016;2(4):70-73.doi: 10.17511/joog.2016.i04.05. 